\title{
Liquefaction Potential Analysis in Bucharest City as a Result of the Ground Shaking during Strong Vrancea Earthquakes
}

\begin{abstract}
By Andrei Bala ${ }^{*} \&$ Dieter Hannich ${ }^{ \pm}$
Bucharest, the capital of Romania with about 2.5 million inhabitants, is frequently struck by intense, damaging earthquakes (2-3 events per century). The Collaborative Research Center 461 (CRC-461) entitled: "Strong Earthquakes a Challenge of Geosciences and Civil Engineering" was established in July 1996 and ended in December 2007, but some projects continued until 2010. It was funded by the German Research Foundation and involved the University of Karlsruhe which today belongs to Karslruhe Institute of Technology. The CRC aimed strategic research in the field of strong earthquakes with regional focus on the Vrancea seismic events in Romania. Between 1995-2007 several research works were done in Romania, with the support of several Romanian research institutes and the University of Bucharest. One of the research questions was to study the occurring of liquefaction during strong earthquakes within the shallow sandy layers in Bucharest. In suitable conditions, strong earthquakes can cause, under certain geologic conditions, liquefaction and therewith ground failure as sand boils, lateral spreading, or differentiated subsidence. In the present paper we analyze the liquefaction risk for Bucharest. For this purpose, at 10 representative sites in Bucharest, Seismic Cone Penetration Tests (SCPTu) were executed. An area-wide evaluation of the liquefaction probability in Bucharest was established. The factor of safety $\left(F_{S}\right)$ against liquefaction and the probability of liquefaction $\left(P_{L}\right)$ were computed from the obtained test-data. For the first time, maps of the liquefaction potential index $\left(L_{i}\right)$ for Bucharest were outlined. This map shows how severe the liquefaction phenomena might be during strong Vrancea earthquakes in Bucharest, amplifying the site effects.
\end{abstract}

Keywords: hydrogeologic conditions, liquefaction probability, liquefaction hazard, Bucharest city, strong Vrancea earthquakes

\section{Introduction}

The shallow geologic underground of Bucharest, which is represented by Quaternary sediments, is characterized by an alternation of soft cohesive and noncohesive soil layers down to $300 \mathrm{~m}$ depth in the northern part. Within this sequence, several main aquifers, exist, presenting specific seasonal variations and long-time trends of the groundwater level. The particular geologic and hydrogeologic conditions existing in Bucharest raise the question if during strong Vrancea earthquakes, liquefaction can take place and if liquefaction-induced ground failure can occur. The only observation of liquefaction occurrence in

\footnotetext{
*Senior Research Geophysicist, National Institute for Earth Physics, Romania.

${ }^{ \pm}$Senior Geologist, Karlsruhe Institute of Technology, Germany.
} 
Bucharest during the strong 1977 Vrancea earthquake is limited to a small area along the old riverbed of the Dambovita. Here was described sand boils aligned along fissures of several meters developed in the covering cohesive soils. This site was then investigated by standard penetration tests (SPT), followed by laboratory tests of the ejected sand and finally the factor of safety was computed (Ishihara and Perlea 1984).

\section{Geology of Bucharest Area}

The area of Bucharest is situated within the regional geological unit of the Moesian Platform, western part, which dates since the beginning of the Paleozoic era. After a sedimentary subsidence of the Carpathian foredeep during the Upper Tertiary and Quaternary, an asymmetric sedimentary basin results, Bucharest being situated at the southern margin of this southward thinning basin (Mutihac 1990). The thickness of the Tertiary sediments, reaching $8000 \mathrm{~m}$ near the Carpathian Arc Bend, appears reduced in the central area of Bucharest to about 500-1000 m (since Ciugudean and Martinof 2000). The Quaternary alluvial and lacustrine deposits are having in the area of Bucharest a thickness of about 200$300 \mathrm{~m}$ (since Liteanu 1952). Holocene loess-like sediments, recent alluvial material and anthropogenic backfill overly on the top the Quaternary deposits.

\section{Classification of the Quaternary Deposits}

A first classification on the geological and lithological description of the Quaternary deposits in the Bucharest area was made by Liteanu (1952). This classification of 7 main layers (beginning from the surface to depth) although rather old was considerably improved through the researches of Ciugudean and Martinof (2000) and Ciugudean-Toma and Stefanescu (2006), which acquired a considerable database during their work at the Metroul S.A. during the time. The classification was generally accepted in the first part of XXI century by all researchers in their studies about site conditions and dynamic properties of the sedimentary layers in and around Bucharest City (Lungu et al. 1999, Mandrescu et al. 2004, Bala et al. 2006, Bala et al. 2011).

This classification comprises the following layers (or complex sedimentary packages) with general characteristics:

Layer 1: Anthropogenic backfill and soil, with a thickness varying between 3$10 \mathrm{~m}$.

Layer 2: The Upper clayey-sandy complex represents Holocene deposits of loess, sandy clays and sands. The thickness of this complex varies between 2$5 \mathrm{~m}$ in the "Dambovita-Colentina inter-fluvial domain", $10-16 \mathrm{~m}$ in the northern and southern Plaines (Baneasa-Pantelimon and Cotroceni-Vacaresti) and 3-6 $\mathrm{m}$ in the river meadows.

Layer 3: The Colentina gravel complex bearing the Colentina-aquifer, is a layer containing gravels and sands with varying grain size distribution. The 
thickness is variable, between 1-20 m, lacking in the western part of Bucharest.

Layer 4: The Intermediate clay layer containing up to $80 \%$ hard consolidated clay and calcareous concretions with intercalated thin sand and silt lenses. The thickness of this layer varies between 0-25 m. 4 Geological and geophysical model of the quaternary layers.

Layer 5: The Mostistea sandbank, bearing the Mostistea-aquifer, is a sand layer with sands of medium to fine grain size. The thickness varies in the area of Bucharest between 1-25 m.

Layer 6: The Lacustrine complex, composed by a variation of limy marled clay and fine sands, the grain size $<0.005 \mathrm{~mm}$ consisting about $86 \%$. The upper face of the complex lies at 20-50 m depth, but the thickness varies

from about $60 \mathrm{~m}$ in the southern part of Bucharest to about $130 \mathrm{~m}$ in the North. The variable thickness is due to the underlying Fratesti complex which descents northward.

Layer 7: The Fratesti complex or Lower gravel complex, bearing the "Fratesti aquifer", lies discordant on Pliocene Levantine clay layers. This complex comprehends three thick (10-40 m each) sandy gravel layers (named A, B and C), separated by two marl or clay layers (each of 5-40 m thickness). This thick complex (total thickness 100-180 m), continuous present in the whole area of Bucharest, dips northward, its upper surface lying at about $75 \mathrm{~m}$ depth in the southern part of Bucharest and at about $190 \mathrm{~m}$ depth in the north (see Figure 1).

Figure 1. Cross-Section Showing the Near-Surface Geology in Bucharest

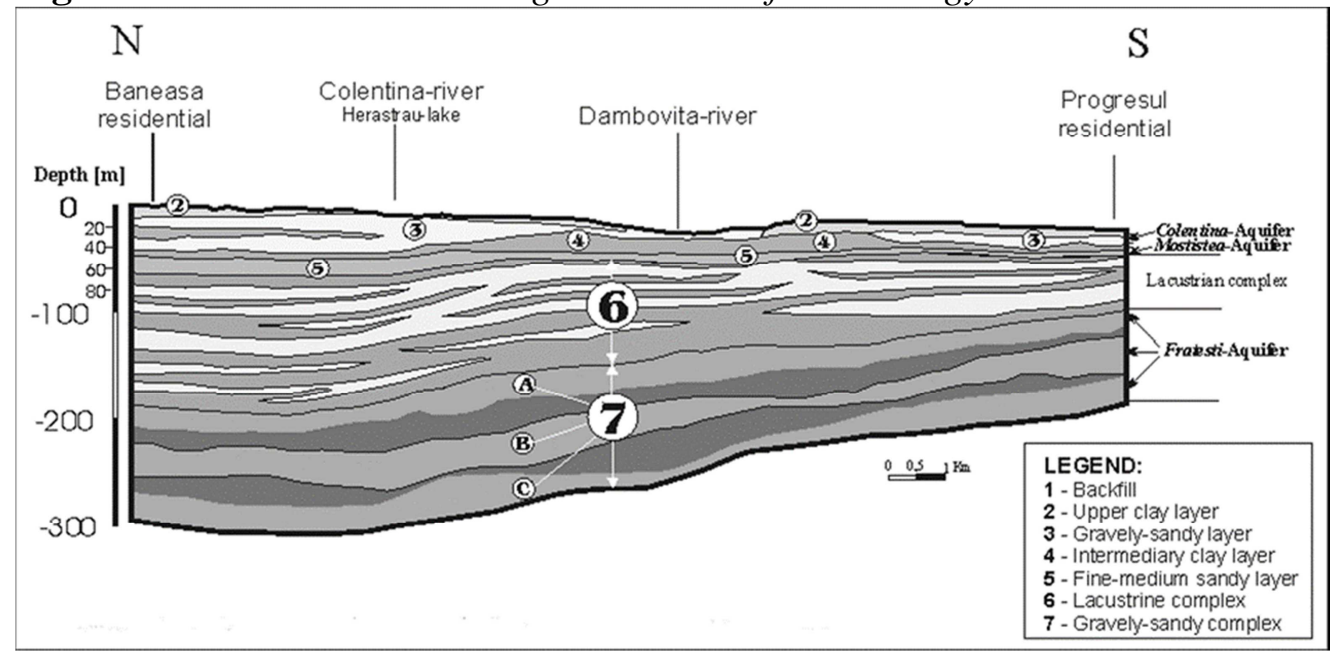

Source: after Bala et al. 2011.

\section{Hydrogeology Characterization of Quaternary Layers}

Complex hydro-geological conditions are characterizing the Quaternary underground of Bucharest. The upper-most aquifer, the Colentina-aquifer is an unconfined aquifer in direct hydraulic connection with the alluvial deposits of the two rivers crossing Bucharest, Colentina and Dambovita. Depending on the 
geomorphologic units in the area of Bucharest, the phreatic groundwater level presents variable depths: a higher level, between 1 and $5 \mathrm{~m}$ depth in the Dambovita and Colentina meadows, between 5 and $10 \mathrm{~m}$ in the Dambovita-Colentina interfluvial domain and below $10 \mathrm{~m}$ in the Cotroceni-Vacaresti and Baneasa-Pantelimon Plains (after Bretotean et al. 1986). Within this aquifer the average permeability (k) lies between $1.2 \times 10^{-4}$ and $9.7 \times 10^{-5} \mathrm{~m} / \mathrm{s}$ (Ciugudean and Martinof 2000).

The second, deeper aquifer, the Mostistea-aquifer presents large variations of thickness in the area of Bucharest and it is mainly a confined aquifer. The Mostistea-aquifer is connected to the mentioned Mostistea-sandbanks, composed of sands with mostly fine to medium grain size, but being also at any places in hydraulic contact with the overlying Colentina-aquifer and also especially in the southern part of Bucharest with the surface water system; so there are zones where Mostistea-aquifer is losing its confined character and it is in communication with the upper-most Colentina-aquifer. The average permeability (k) lies between $5 \times 10^{5}-8.3 \times 10^{-5} \mathrm{~m} / \mathrm{s}$.

The deepest Quaternary aquifer is thicker (depths of 100-300 $\mathrm{m}$ and thickness of $100-150 \mathrm{~m}$ ); the Fratesti-aquifer is situated at the base of the Quaternary layers. It is a regional aquifer system with three distinguished aquifers named A, B and C, each of these having 10-40 m thick, being extended continuously in the southern part of Romania, dipping toward the Carpathians and outcropping near the Danube. The most important aquifer of this system is the layer A, being mainly used for drinking water extraction (Bretotean 2001). Due to its relative great depth, it is considered outside of the near-surface geology range and without importance for liquefaction. The permeability of the uppermost layer " $A$ " within the Fratestiaquifer lies at about $1.3 \times 10^{-4}-5.4 \times 10^{-5} \mathrm{~m} / \mathrm{s}$ (Ciugudean and Martinof 2000).

\section{Liquefaction Occurring Conditions}

The knowledge of the local hydrogeological conditions plays also an important role in analysing the saturation of the soil and the pore water pressure increasing and implicit liquefaction occurrence.

The depth of groundwater influences liquefaction susceptibility and plays a significant role in Bucharest (Hannich et al. 2005). It decreases significantly with increasing depth of groundwater level. Thus it is necessary to know exactly the hydrogeologic conditions, the type of aquifers (confined or unconfined), the piezometric level for each aquifer, the groundwater flow direction and the groundwater level variations in time (seasonal and long-time variations). For Bucharest the two near-surface aquifers, Colentina and Mostistea, are of interest for the evaluation of their liquefaction susceptibility. The depth of the groundwater level (Figure 2a), its seasonal variation and long-time trends (Figure 3) and the confined and unconfined character within these aquifers (Figure 2b) are deduced from long-time monitoring data. The variation of the groundwater level depth due to seasonal or extreme precipitation events, influences as well, as long-time trends can influence significantly the liquefaction susceptibility of these aquifers. 


\section{Piezometric Observations of Aquifers in Bucharest}

For Bucharest there are continuous piezometric observations for the three main aquifer systems since 1973, executed in representative piezometric boreholes belonging to the National Institute for Hydrology and Water Management in Bucharest. Through recorded long-term variations, the difference between the deepest groundwater level and the highest level in the period 1973-2002 comprises 4-5 m, while seasonal variations can reach up to 2-3 m (Figure 3). These observed groundwater fluctuations in Bucharest, can lead to variations of the water saturation within a sand layer from $0-100 \%$, with direct consequence upon the value of the shear wave velocity and the variation of the liquefaction potential (Ehret et al. 2010).

Figure 2. a) Depth of Groundwater Level in Bucharest, Measured in January 2004 (Original Data from METROUL S.A. and INHGA, Bucharest) b) Confined and Unconfined Domains of the Groundwater in the "Colentina"-Aquifer in January 2004. Red Circles - 10 SCPT Sites; Pink Dots - Piezometric Boreholes

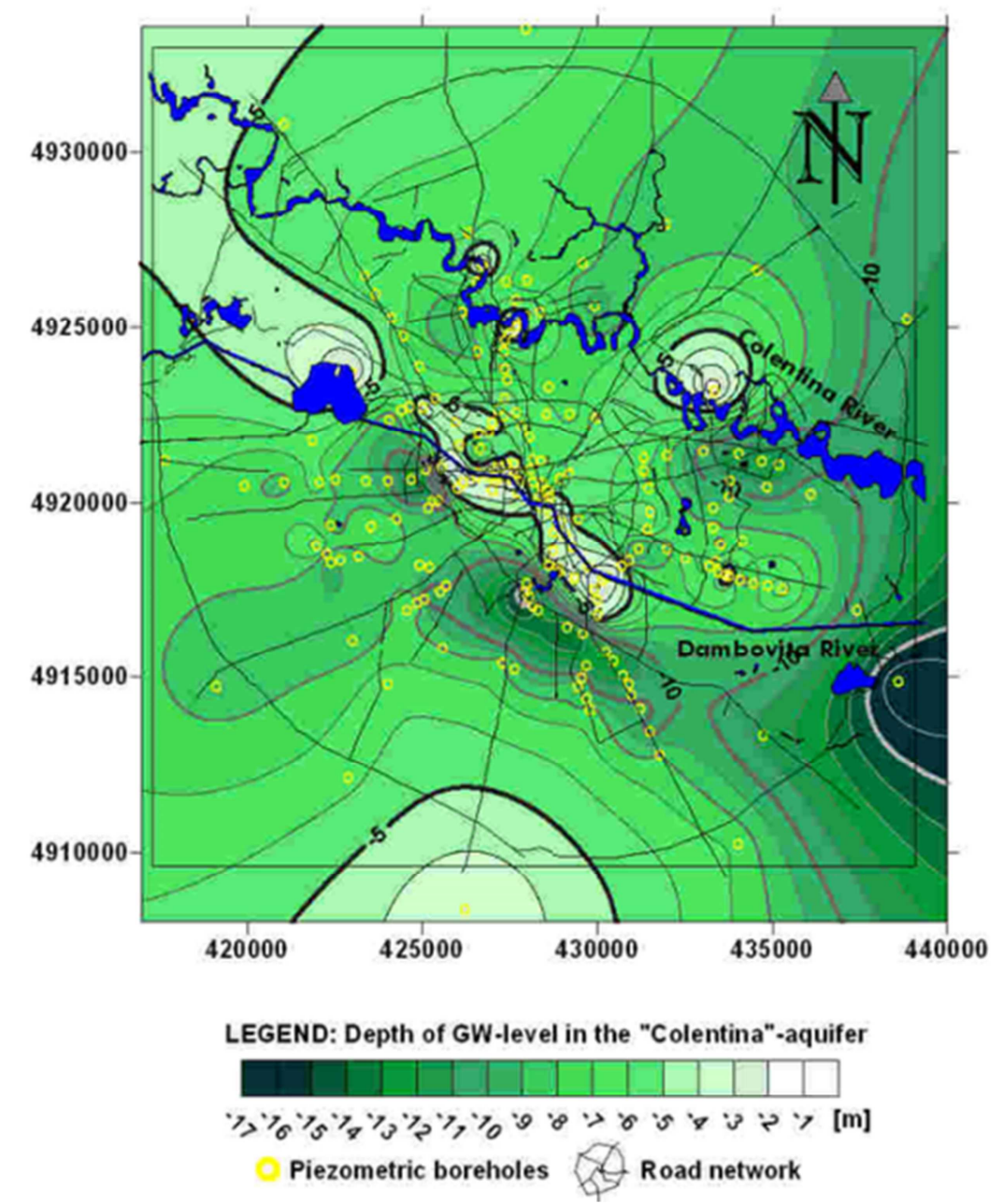

a) 


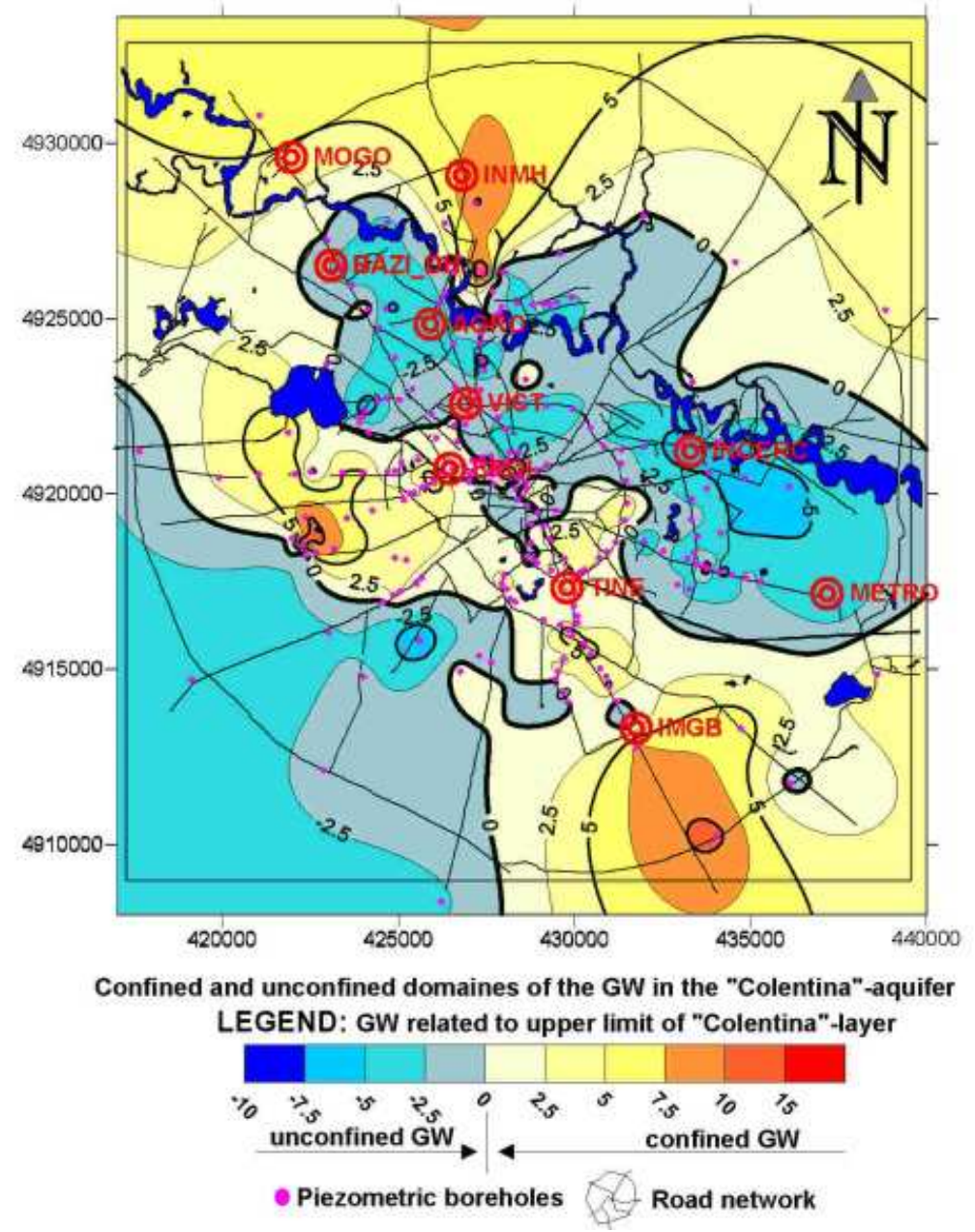

b)

Quasi-simultaneous groundwater level measurements within the Colentinaaquifer in about 230 hydrogeologic boreholes scattered over Bucharest City were beginning in 2004. In Figure 2a the depth of the groundwater level, as depths from the ground level in Bucharest in the Colentina-aquifer, is presented. Based on these data, a map is obtained describing the confined or unconfined state of the groundwater in the gravely-sandy Colentina-layer (Figure 2b). This information is necessary for the evaluation of the liquefaction potential in Bucharest.

Monitoring of groundwater level variations in the last years in some representative groundwater-boreholes within the Colentina-aquifer made possible to obtain records during extreme precipitation events. These show the speed of rise and decrease of the groundwater level in correlation with the precipitation event.

It was proved that groundwater and groundwater level changes have a very important influence on site effects. If confined aquifers exist near the surface liquefaction can take place. Under certain conditions one can benefit from the existence of liquefied layers as they attenuate the propagation of shear waves (Ehret et al. 2010).

The medium-to-fine sands of the Mostistea layer and the alluvial sands in the Dambovita meadow, fit to the easy-liquefiable area. Fluvial and alluvial 
environments present frequently rounded particles. For Bucharest these insights allow the acceptance that the sandy-gravely Colentina layer is liquefaction susceptible, if other influencing criteria are also fulfilled (Figure 2a). From this point of view the alluvial soils in the river meadows in Bucharest are favorable for liquefaction susceptibility.

Figure 3. Upper Part: Annual Variations of the Groundwater in the ColentinaAquifer during Different Years (1977, 1985, 2000, 2001) in Pipera Borehole. Lower Part: Annual Precipitations in [l/m²] during 1977, 1985, 2001.

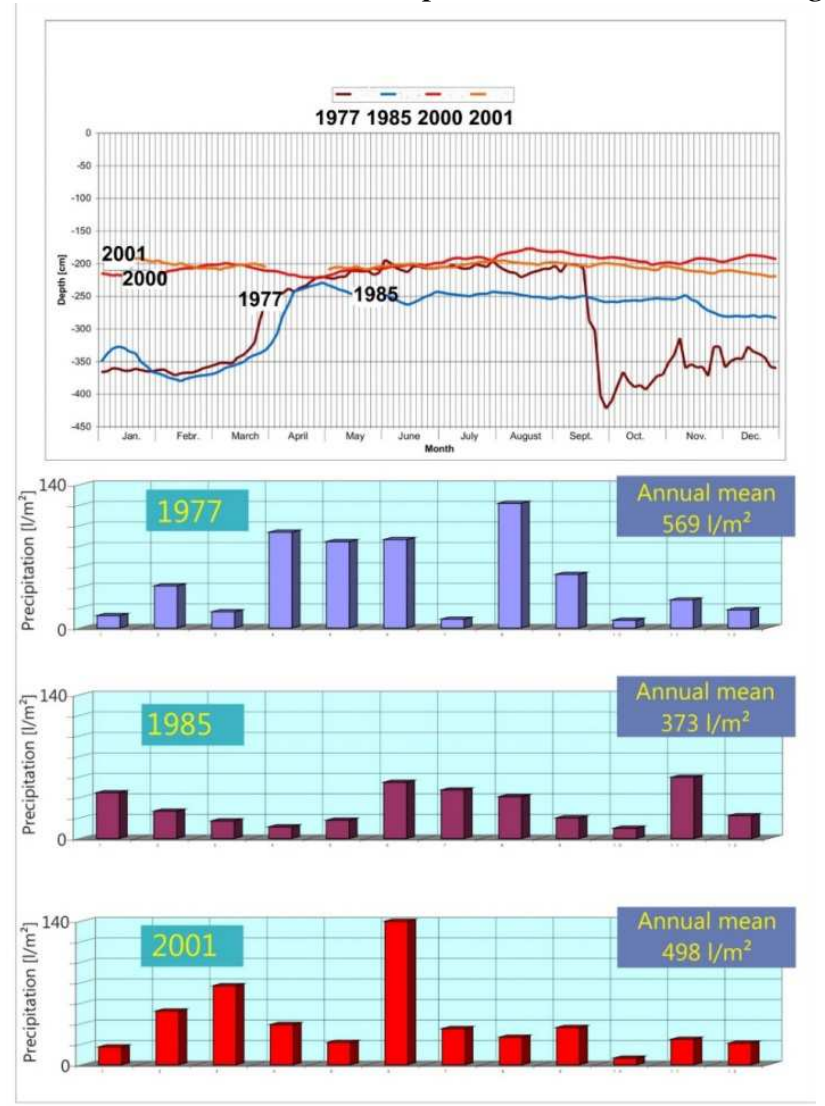

Composition of shallow Quaternary layers refers to grain size distribution, gradation and particle shape. For many years, liquefaction-related phenomena were thought to be limited to sands as finer-grained soils were considered incapable of generating the high pore water pressure associated with liquefaction. It was observed in laboratory and in the field that even non-plastic silts can liquefy (Kramer 1996). It was observed also that gravely soils are susceptible for liquefaction if undrained conditions are assured by the presence of impermeable layers above and beneath the gravely layer (Kramer 1996). Only plastic clays remain non-susceptible for liquefaction.

The medium-to-fine sands of the Mostistea layer and the alluvial sands in the Dambovita meadow, fit to the easy-liquefiable area. Fluvial and alluvial environments present frequently rounded particles. For Bucharest these insights allow the acceptance that the sandy-gravely Colentina layer is liquefaction 
susceptible, if other influencing criteria are also fulfilled (Figure 2a). From this point of view the alluvial soils in the river meadows in Bucharest are favorable for liquefaction susceptibility.

\section{Case Study in Bucharest City and Discussion}

\section{Cone Penetration Testing (CPT) Method}

The analysis of the liquefaction probability, the potential of liquefaction and of ground failure at a site can be evaluated using data from Cone Penetration Tests (CPT). The evaluation procedure is based on empirical equations deduced by different authors (Olsen 1997, Robertson and Wride 1998, Chen and Juang 2000, Lee et al. 2003, Yuan et al. 2004). All these empirical methods follow the general stress-based approach of Seed and Idriss (1971) and require the determination of two variables, namely, the cyclic stress ratio (CSR) and the cyclic resistance ratio (CRR). Since 1971, the determination of CSR, as proposed by Seed and Idriss (1971), representing the cyclic load in simplified methods, remained unmodified.

For the determination of CRR, different simplified methods have been proposed till today. In this paper the method proposed by Olsen (1997) is applied for the determination of CSR and CRR and was already described at length by Hannich et al. (2006a) and (2007).

For Bucharest, in the determination of CSR, the characteristics of the Vrancea earthquake of 1977 were used: for $\mathrm{Mw}=7.4$ and peak ground acceleration (i.e., PGA-values) at different sites in Bucharest deduced by a method proposed by Sokolov and Bonjer (2006) and Sokolov et al. (2008).

The factor of safety (Fs) is determined after Lee et al. (2003) as:

$$
F_{s}=C R R / C S R_{7.5}
$$

Probability of Liquefaction $P_{L}$

The probability of liquefaction, $P_{L}$ can be estimated after Juang et al. (2003) by Eq. (2):

$$
P_{L}=\frac{1}{1+\left(F_{s} / 0.96\right)^{4.5}}
$$

where $F s$ is the factor of safety defined by Eq. (1).

After Chen and Juang (2000), the liquefaction will occur only if the probability of liquefaction is greater than $35 \%$.

Soil Type Index, Ic

Starting also from the CPT-data the soil type index, Ic, defined by Robertson and Wride (1998), a detailed lithological depth profile can be obtained. The index 
Ic is calculated by Eq. 3 and depends on the normalized stress-adjusted cone tip resistance (Eq. 4) and the normalized friction ratio $F$ (Eq. 5):

$$
I_{c}=\left[\left(3.47-\log \left(q_{c 1 N}\right)\right)^{2}+(\log F+1.22)^{2}\right]^{0.5}
$$

where $q_{c 1 N}=$ normalized (stress-adjusted) cone penetration resistance, defined as

$$
q_{c 1 N}=10\left[q_{c} /\left(\sigma_{v}^{\prime}\right)^{0.5}\right],(\text { all terms in } \mathrm{kPa})
$$

$\mathrm{F}=$ normalized friction ratio, defined as

$$
F=f_{s} /\left(q_{c}-\sigma_{v}\right) \times 100 \%
$$

The soil type index $I c$ helps among others to restrict the probability of liquefaction to soils with $I c<2.8$ (Yuan et al. 2004).

\section{Liquefaction Potential Index, $\mathrm{Li}$}

The liquefaction potential index $\mathrm{Li}$ is used to evaluate the ground failure risk. Its severity categories were proposed originally by Iwasaki et al. (1982) and modified by Sonmez (2003), which proposed the change of the threshold value of Fs between non-liquefiable and liquefiable layers from 1.0 to 1.2 and suggested the following equations:

$$
L_{i}=\int_{0}^{20} F(z) \cdot W(z) \cdot d z
$$

$$
\begin{array}{lc}
F(z)=1-F_{s} & \text { for } F_{s}<0.95 \\
F(z)=2 * 10^{6} * \operatorname{EXP}\left(-18.427 * F_{s}\right) & \text { for } 0.95<F_{s}<1.2 \\
F(z)=0 & \text { for } F_{s}>1.2 \\
W(z)=10-0.5 * z & \text { for } \leq z \leq 20 \mathrm{~m} \\
W(z)=0 & \text { for } z \geq 20 \mathrm{~m} . \\
z=\text { depth } &
\end{array}
$$

To interpret the obtained values of $L i$ (Eq. 6), a classification is used in Table 1 , after several studies.

$\mathrm{Li}$ et al. (2006) have assumed threshold probability of 0.35 as the border between liquefaction/no liquefaction. They also suggested that LPI=5 can still be used as a lower bound of failure cases below which no liquefaction-induced ground failure is expected whereas LPI $=13$ is used as boundary for high and very high liquefaction risk. 
Table 1. Liquefaction Potential Index $L_{i}$ Classification Index

\begin{tabular}{|c|c|c|c|}
\hline \multicolumn{3}{|c|}{ Liquefaction potential index $\mathbf{L}_{\mathbf{i}}$} & \multirow{2}{*}{$\begin{array}{c}\text { Liquefaction potential } \\
\text { category }\end{array}$} \\
\cline { 1 - 3 } Iwasaki (1982) & Lee et al. (2003) & $\begin{array}{c}\text { Li et al. } \\
(\mathbf{2 0 0 6 )}\end{array}$ & $\begin{array}{c}\text { Non-liquefiable (based on } \\
\left.F_{s}<1.2\right)^{* * *}\end{array}$ \\
\hline 0 & 0 & 0 & Low \\
\hline $0<L_{i}<2$ & $0<L_{i}<2$ & $0<L_{i}<2$ & Moderate \\
\hline $2<L_{i}<5$ & $2<L_{i}<8^{*}$ & $2<L_{i}<5$ & High \\
\hline $5<L_{i}<15$ & $8<L_{i}<16^{* *}$ & $5<L_{i}<13$ & Very high \\
\hline $15>L_{i}$ & $16>L_{i}$ & $13>L_{i}$ & \\
\hline
\end{tabular}

*for CRR calculated after Olsen (1997) this value is 8 (Lee et al. 2003).

**for CRR calculated after Olsen (1997) this value is 16 (Lee et al. 2003).

***modified by Sonmez (2003).

The liquefaction potential index proposed by Lee et al. (2003) is used to evaluate the severity of the liquefaction induced ground failure.

\section{SCPTu-Measurements in Bucharest}

The first systematic research of seismic site effects take place between 19972007, within the Collaborative Research Centre (CRC-461) performed by the University of Karlsruhe, Germany in collaboration with several research institutes from Bucharest, Romania.

Seismic Cone Penetration Tests (SCPTu) were executed in Bucharest at 10 representative sites, located in the river meadow of the Dâmbovița River, in the inter-fluvial domain and in the Northern and Southern Plains (see Figure 2b). In Bucharest it was possible to reach depths of $35 \mathrm{~m}$. Through the continuously recorded cone (tip resistance and the sleeve friction) it was possible to get detailed lithological profiles, soil type index profiles and the factor of safety over the depth using empirical methods. These data are used to calculate the liquefaction potential index and the liquefaction severity index, over a $20 \mathrm{~m}$-depth interval. Based on these indicators the contour maps of the liquefaction potential and of the severity of liquefaction were outlined for Bucharest City.

Seismic Cone Penetration Tests (SCPTu) were carried out in Bucharest in order to determine missing data on shear wave velocities for the near-surface area (depths $0-35 \mathrm{~m}$ ). At the same time important geotechnical data on the tip resistance and the sleeve friction are obtained, which should enable the probability of the occurrence of soil liquefaction using empirical methods. The SCPTu measurements were carried out at 10 selected locations in Bucharest (Figure 2b). The principle of the measurements as well as the mathematical principles and formulas that are required for the evaluation of the CPT data are described in the paper (Hannich et al. 2006b).

The results of the shear wave velocities determined by SCPTu are given in Table 2 for layers 2-6 in Bucharest. 
Table 2. Results of the Shear Wave Velocities Determined through Seismic Cone Penetration Tests (SCPTu) in Bucharest for the Near-Surface Depths $(0-35 \mathrm{~m})$

\begin{tabular}{|l|c|c|c|c|c|}
\hline \multirow{2}{*}{$\begin{array}{l}\text { Layer no./ } \\
\text { Location }\end{array}$} & $\begin{array}{c}\text { 2.Upper } \\
\text { Clay } \\
\text { layer }\end{array}$ & $\begin{array}{c}\text { 3.Colentina } \\
\text { aquifer }\end{array}$ & $\begin{array}{c}\text { 4.Intermediate } \\
\text { Clay layer }\end{array}$ & $\begin{array}{c}\text { 5.Mostiștea } \\
\text { aquifer }\end{array}$ & $\begin{array}{c}\text { 6.Lacustri } \\
\text { ne layer }\end{array}$ \\
\cline { 2 - 6 } & \multicolumn{6}{|c|}{ Shearwave velocity Vs (m/s) } \\
\hline BAZI & 291 & 194 & 295 & 308 & 307 \\
\hline AGRO & 332 & 296 & 320 & - & - \\
\hline VICT & 282 & 252 & 303 & - & - \\
\hline INCERC & 295 & 311 & 320 & - & - \\
\hline IMGB & 223 & 275 & - & - & - \\
\hline INMH & 236 & - & 283 & 434 & - \\
\hline METRO & 296 & 292 & 261 & 320 & 355 \\
\hline MOGO & 272 & 244 & 294 & 363 & - \\
\hline TINE & 167 & 256 & 361 & - & - \\
\hline EROI & 230 & 209 & 253 & 301 & 336 \\
\hline Average & 278 & 266 & 300 & 345 & 333 \\
\hline
\end{tabular}

Source: after Hannich and Hötzl (2008).

\section{Liquefaction Potential in Bucharest City}

In this paper the calculations were outlined for the 1977-Vrancea earthquake of magnitude $\mathrm{Mw}=7.4$, which supposed to generate the PGA computed values which are presented in the Table 3 for each site.

Starting from the magnitude of 7.4 of the 1977 Vrancea-earthquake and the deduced PGA-values (Sokolov and Bonjer 2006, Sokolov et al. 2008) at the ten SCPTu-sites in Bucharest, the factor of safety $(F s)$, the probability of liquefaction $(P l)$, the liquefaction potential index $(L i)$ as well as the liquefaction severity index (Ls) were calculated. Table 3 contains the summarized results for Bucharest during the 1977 earthquake. It can be seen, that the highest liquefaction potential category ("High") and the highest liquefaction severity class ("Moderate") were obtained for the TINE and EROI sites, in the Tineretului Park. This result agrees with the observed and induced (man-made) liquefaction phenomena which were observed in 2015 and described in the Annex 1 of the present paper.

In Table 3 (column 3) the shearwave velocities are obtained by Bala et al. (2011) as $\boldsymbol{V}_{\mathbf{S}-30}$ computed in the specific sites. In column 5 the values of peak ground acceleration (PGA) are computed according to Sokolov and Bonjer (2006) for an earthquake with the same magnitude as the event from 04.03.1977. 
Table 3. Liquefaction Risk Analysis for Bucharest City

\begin{tabular}{|c|c|c|c|c|c|c|c|c|}
\hline No. & Name & $\begin{array}{c}\mathrm{V}_{\mathrm{S}-30} \\
\text { Share- } \\
\text { wave } \\
\text { velocity } \\
{[\mathrm{m} / \mathrm{s}]}\end{array}$ & $\begin{array}{c}\text { Water } \\
\text { Level } \\
\text { GW } \\
{[\mathbf{m}]}\end{array}$ & $\begin{array}{c}\text { Deduced } \\
\text { PGA } \\
{\left[\mathrm{m} / \mathbf{s}^{2}\right]^{*}}\end{array}$ & $\mathbf{L}_{\mathrm{s}}$ & $\begin{array}{l}\text { Liquefaction } \\
\text { severity class }\end{array}$ & $\mathbf{L}_{\mathbf{i}}$ & $\begin{array}{c}\text { Liquefaction } \\
\text { potential } \\
\text { category** }\end{array}$ \\
\hline \multirow{2}{*}{1} & \multirow{2}{*}{ TINE } & \multirow{2}{*}{237} & \multirow{2}{*}{-1.8} & 2.6 & 38.89 & Moderate & 13.23 & High \\
\hline & & & & 4.0 & 45.25 & Moderate & 18.76 & Very high \\
\hline \multirow[t]{2}{*}{2} & EROI & 287 & -4.2 & 2.5 & 17.72 & Moderate-low & 6.22 & High \\
\hline & & & & 4.0 & 33.38 & $\begin{array}{c}\text { Low- } \\
\text { moderate }\end{array}$ & 9.83 & High \\
\hline 3 & \multirow{2}{*}{ BAZI } & \multirow{2}{*}{267} & -5 & \multirow{2}{*}{3.6} & 22 & Low & 7.5 & High \\
\hline & & & -8.5 & & 27.9 & Low & 16.5 & Very high \\
\hline 4 & MOGO & 281 & -7.5 & 3.5 & 14.56 & Low & 1.91 & Low-Moderate \\
\hline 5 & VICT & 290 & -6 & 3.0 & 16.2 & Low & 1.62 & Low \\
\hline \multirow{2}{*}{6} & \multirow{2}{*}{ AGRO } & \multirow{2}{*}{311} & \multirow{2}{*}{-7.5} & 3.0 & 3.9 & Very Low & 0.64 & Low \\
\hline & & & & 4.5 & 20.77 & Low & 3.53 & Moderate \\
\hline 7 & IMGB & 251 & -8.5 & 2.7 & 2.82 & Very low & 0.15 & Low \\
\hline 8 & INMH & 264 & -10 & 3.0 & 1.19 & Very low & 0.09 & $\begin{array}{c}\text { Non- } \\
\text { liquefaction }\end{array}$ \\
\hline 9 & METRO & 303 & -8.5 & 2.5 & 0.99 & Very low & 0.18 & Low \\
\hline \multirow[t]{2}{*}{10} & \multirow[t]{2}{*}{ INCERC } & \multirow[t]{2}{*}{305} & \multirow[t]{2}{*}{-11.5} & 2.5 & 0 & Non-liqu. & 0 & $\begin{array}{c}\text { Non- } \\
\text { liquefaction }\end{array}$ \\
\hline & & & & 4.0 & 7.06 & Very low & 0.32 & Low \\
\hline
\end{tabular}

* Liquefaction severity classification after Sonmez and Gokceoglu (2005).

** Liquefaction potential category after Sonmez (2003).

We discuss first the obtained results for three sites, at the locations in which the liquefaction potential index have high values (Table 3): TINE (Figure 4a); EROI (Figure 4b) and BAZI (Figure 4c).

In Figure 4a it can be observed, that at TINE for a PGA-value of $2.6 \mathrm{~m} / \mathrm{s}^{2}$ and for a depth interval of $12 \mathrm{~m}$ (between 6-18 $\mathrm{m}$ depth) the probability of liquefaction is over $35 \%$, partly even $60 \%$. For this site the calculations were performed also for a PGA-value of $4.0 \mathrm{~m} / \mathrm{s}^{2}$, showing an increase of the probability of liquefaction for the same depth interval over $80 \%$. This shows the scale of the influence of PGA upon the liquefaction evaluation.

Not far from the values computed at TINE are the next values computed in Figure $4 \mathrm{~b}$ for the site EROI. The evaluation was performed for a PGA-value of 4 $\mathrm{m} / \mathrm{s}^{2}$ and presents a probability over $80 \%$ for a depth interval above the ground water.

In Figure $4 \mathrm{c}$ the calculation results at BAZI location are presented. The evaluation was performed for a PGA-value of $3.6 \mathrm{~m} / \mathrm{s}^{2}$ and presents a probability over $80 \%$ for a depth interval of $6 \mathrm{~m}$ (between $7 \mathrm{~m}$ and $13 \mathrm{~m}$ ). For this site, calculations for a $3.5 \mathrm{~m}$ higher groundwater level were performed also, showing an increase of the probability up to nearly $100 \%$ and also an increase over $60 \%$ for a deeper depth interval. 
Figure 4. a) Liquefaction Evaluation at the TINE Location for $P G A=2.6 \mathrm{~m} / \mathrm{s}^{2}$ b) Liquefaction Evaluation at the EROI Location for $P G A=4.0 \mathrm{~m} / \mathrm{s}^{2}$ c) Liquefaction Evaluation at the BAZI Location $P G A=3.6 \mathrm{~m} / \mathrm{s}^{2}$.

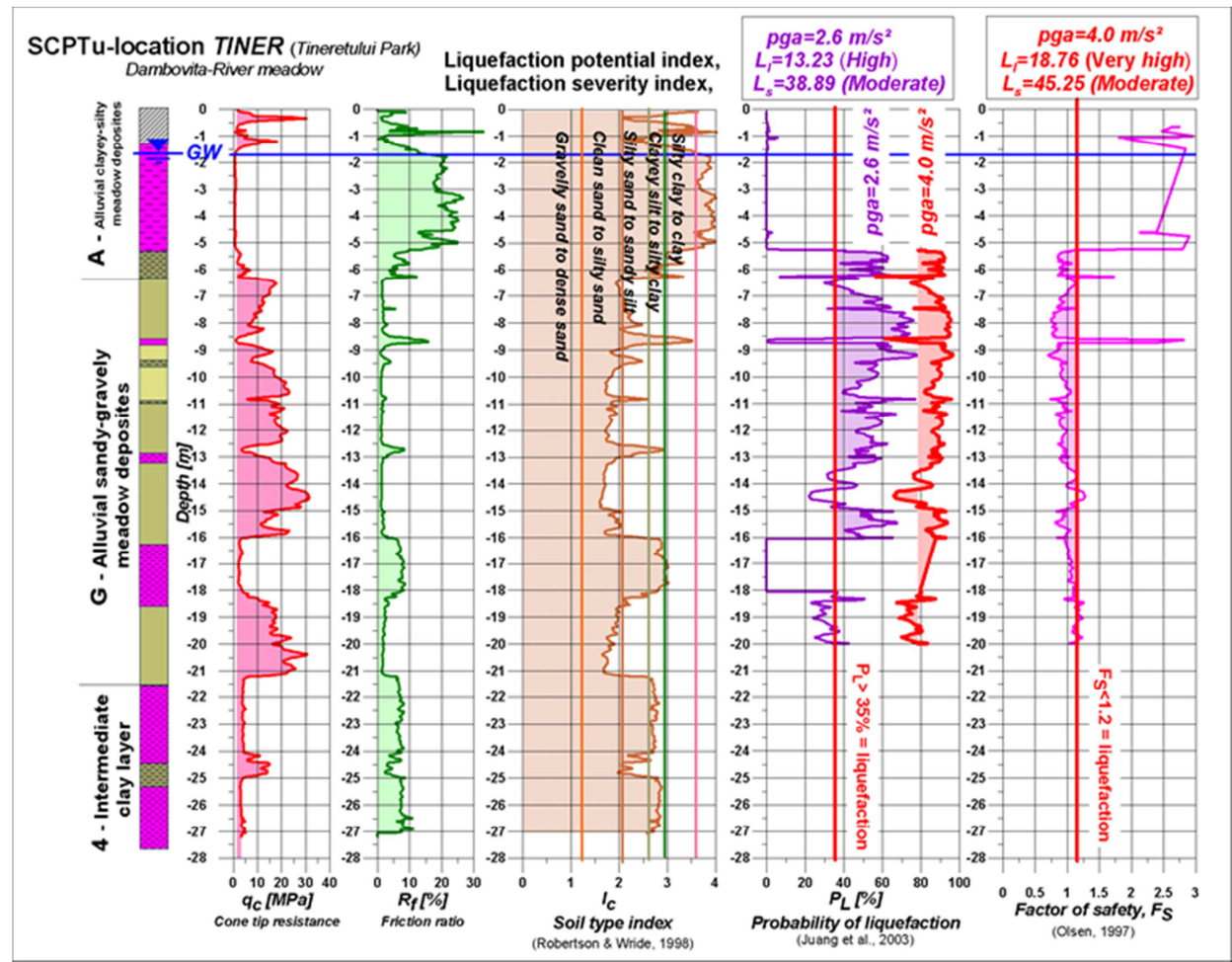

a)

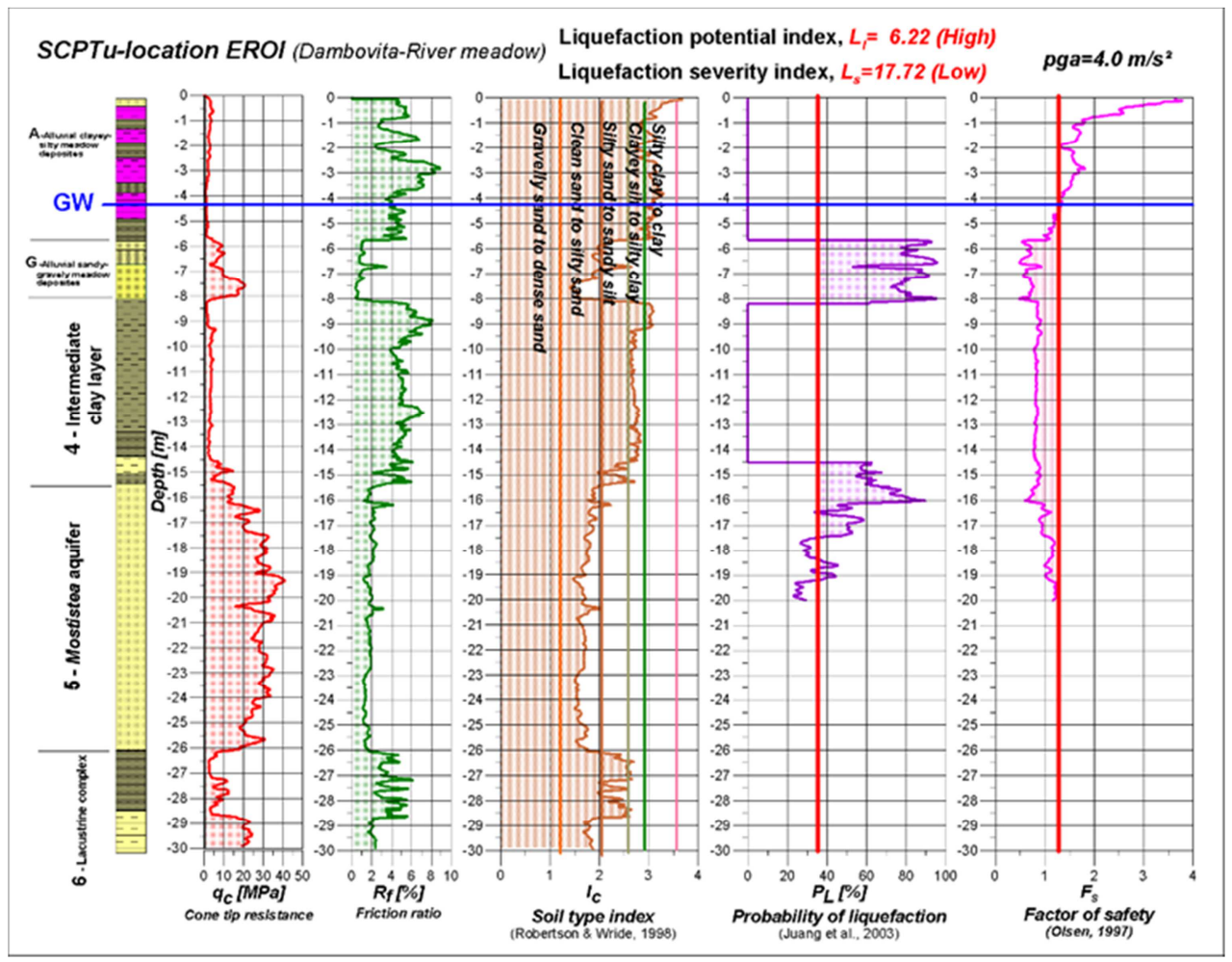

b) 


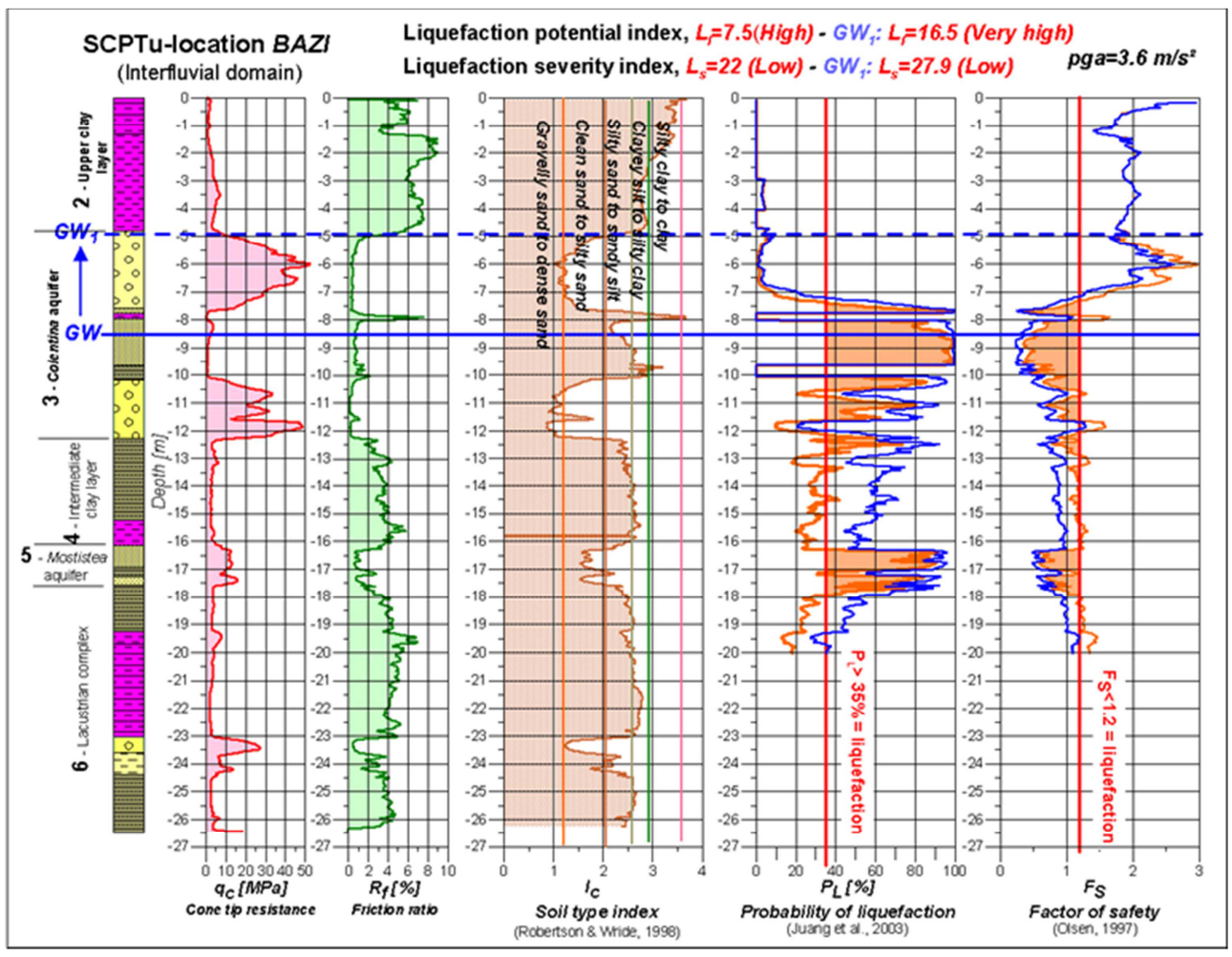

c)

The Influence of the Local PGA-Value

The local PGA-value recorded in a site, influences directly the factor of safety Fs through the CSR-value. To observe the scale of this influence, for the TINE site and the BAZI site the liquefaction probability was calculated for PGA-values of $2.5 \mathrm{~m} / \mathrm{s}^{2}$ and of $4.0 \mathrm{~m} / \mathrm{s}^{2}$ (Figure $4 \mathrm{a}$ and Figure $4 \mathrm{~b}$ ). At the location TINE (Figure 4a) the liquefaction probability increase very strong for a higher PGA-value, the liquefaction potential became "very high", but the liquefaction severity remains "moderate". In Figure $4 \mathrm{~b}$ it can be seen, that for $2.5 \mathrm{~m} / \mathrm{s}^{2}$ the probability is lower than $35 \%$, but for $4.0 \mathrm{~m} / \mathrm{s}^{2}$ the probability became greater than $60 \%$ and even $80 \%$, but only for thin soil layers. The liquefaction potential became from "nonliquefiable" to "low" and the liquefaction severity became from "non-liquefiable" to "very low". The liquefaction severity increases only a little, also due to the great thickness (about $6 \mathrm{~m}$ ) of the covering clay layer. It can be said, that for a stronger earthquake than the 1977 one, at greater PGA-values, liquefaction effects can appear also at some new sites that until now were considered as "non-liquefiable".

Analysis of the Influence of Groundwater Level Variations for Liquefaction in Bucharest

Seasonal groundwater level variations and groundwater level variations due to extreme precipitation events must be taken into account as a main time-variable influencing factor for liquefaction in Bucharest. The extend of the groundwater level variations within the upper-most aquifer, the Colentina aquifer was studied by continuous level-records during the research period of the CRC-461 project. To emphasize the scale of the influence of groundwater level variations, the 
liquefaction probability and the other liquefaction indices were calculated for different groundwater level. In Figure $4 \mathrm{c}$ these differences are presented for the case of the BAZI location. It can be seen, that for a $3 \mathrm{~m}$ higher groundwater level, the probability of liquefaction increase for the whole depth interval of $12 \mathrm{~m}$, but especially for the depth interval between 13-16 m, where the probability was below $35 \%$, it is now greater than $50 \%$. The liquefaction potential became from "high" to "very high", but the liquefaction severity remains "moderate", mainly due to the great thickness (about $5 \mathrm{~m}$ ) of the covering clay layer at this site.

Further it can be shown, that changes of groundwater level influence the ground response significantly and cannot be neglected for site effect analyses (Ehret et al. 2007).

\section{The Influence of Shear-Wave Seismic Velocities}

In Table 1 all the relevant information about the SCPTu measurements perfomed in Bucharest in 10 sites are given after Hannich and Hötzl (2008).

The shallow seismic velocity structure of the uppermost subsurface is the first step in estimating the amplification of earthquake-induced ground motion and for Bucharest it was presented by Von Steht et al. (2008) using classical methods like seismic refraction.

Extensive information about shear-wave seismic velocities are presented by Bala et al. (2011) for the whole Bucharest City and employing several seismic methods adapted to the work in a big city.

Hannich and Orlowsky (2014) presented shear-wave seismic velocities obtained by MULTI-OFFSET VERTICAL SEISMIC PROFILING (MOVSP) measurements and obtained the $\mathrm{V}_{\mathrm{S}}$ characteristic values for the 7 principal Quaternary layers.

Figure 5. Shear-Wave Velocity Evaluation by SCPT at the TINE Location

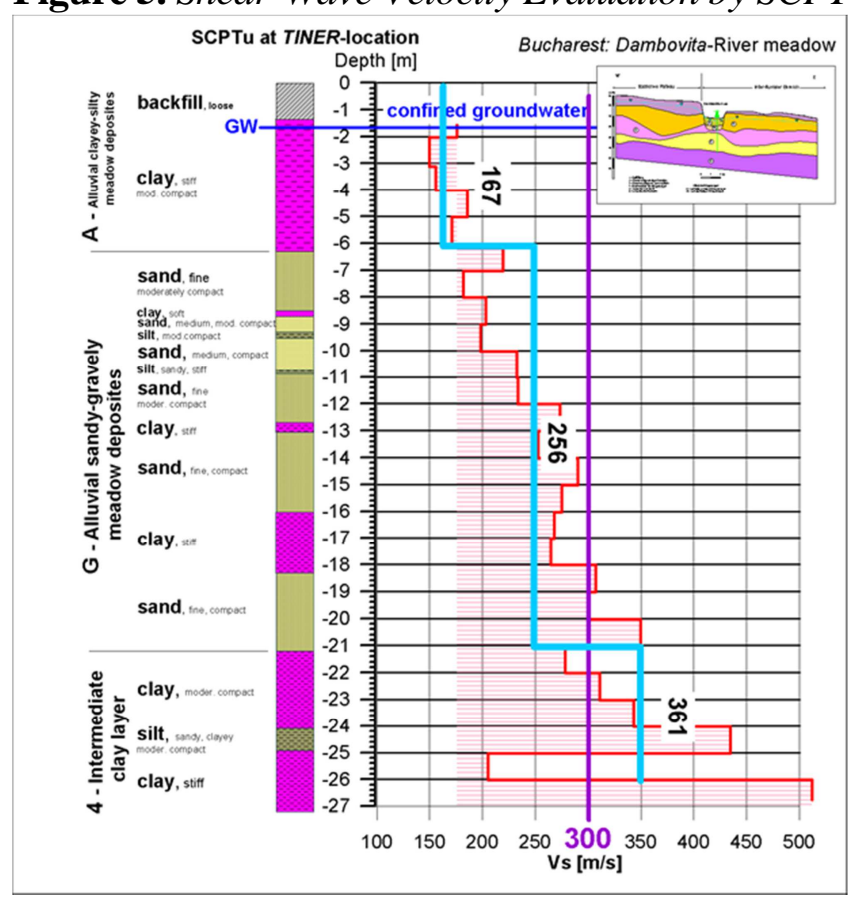


Characteristic for liquefaction prone areas are reduced shear-wave velocities of the near-surface geologic formations. The SCPT-method enabled the detailed determination of the shear-wave velocity at the different locations. As an example, in Figure 5 the variation of the shear-wave velocity until a depth of $27 \mathrm{~m}$ at the TINE location (Tineretului Park) is presented. Reduced shear-wave velocities of about $167 \mathrm{~m} / \mathrm{s}$ were determined here for the first $6 \mathrm{~m}$ depth although the value in the Table 3 is about $237 \mathrm{~m} / \mathrm{s}$, being computed until a depth of $30 \mathrm{~m}$.

In complete contrast with the first 3 sites presented in Figure 4, in Figure 6 the liquefaction evaluation with low and very low values of liquefaction potential index is presented for the sites INMH; METRO; INCERC which are placed outside the river meadow area and to the north-east of the interfluvial domain. For values of PGA in the $2.5-4 \mathrm{~m} / \mathrm{s}^{2}$, the values of liquefaction potential index is close to 0 , showing the lack of possibility of occurring liquefaction. The existence of ground water table at depth around $10 \mathrm{~m}$ is playing a key role along with the composition of the shallow layers in the area. In Figure $6 c$ the liquefaction evaluation for the INCERC location is presented. For a PGA-value of $2.5 \mathrm{~m} / \mathrm{s}^{2}$ estimated here from the ground motion records of the 1977 earthquake, the liquefaction evaluations using CPT-data, show a probability under $35 \%$, that means under that conditions no liquefaction will take place.

Figure 6. Liquefaction Evaluation with low Values of Liquefaction Potential Index at: a) INMH for $P G A=3 \mathrm{~m} / \mathrm{s}^{2}$ b) METRO for $P G A=2.5 \mathrm{~m} / \mathrm{s}^{2}$ c) INCERC $P G A_{1}=$ 2.5 and $P G A_{2}=4.0 \mathrm{~m} / \mathrm{s}^{2}$

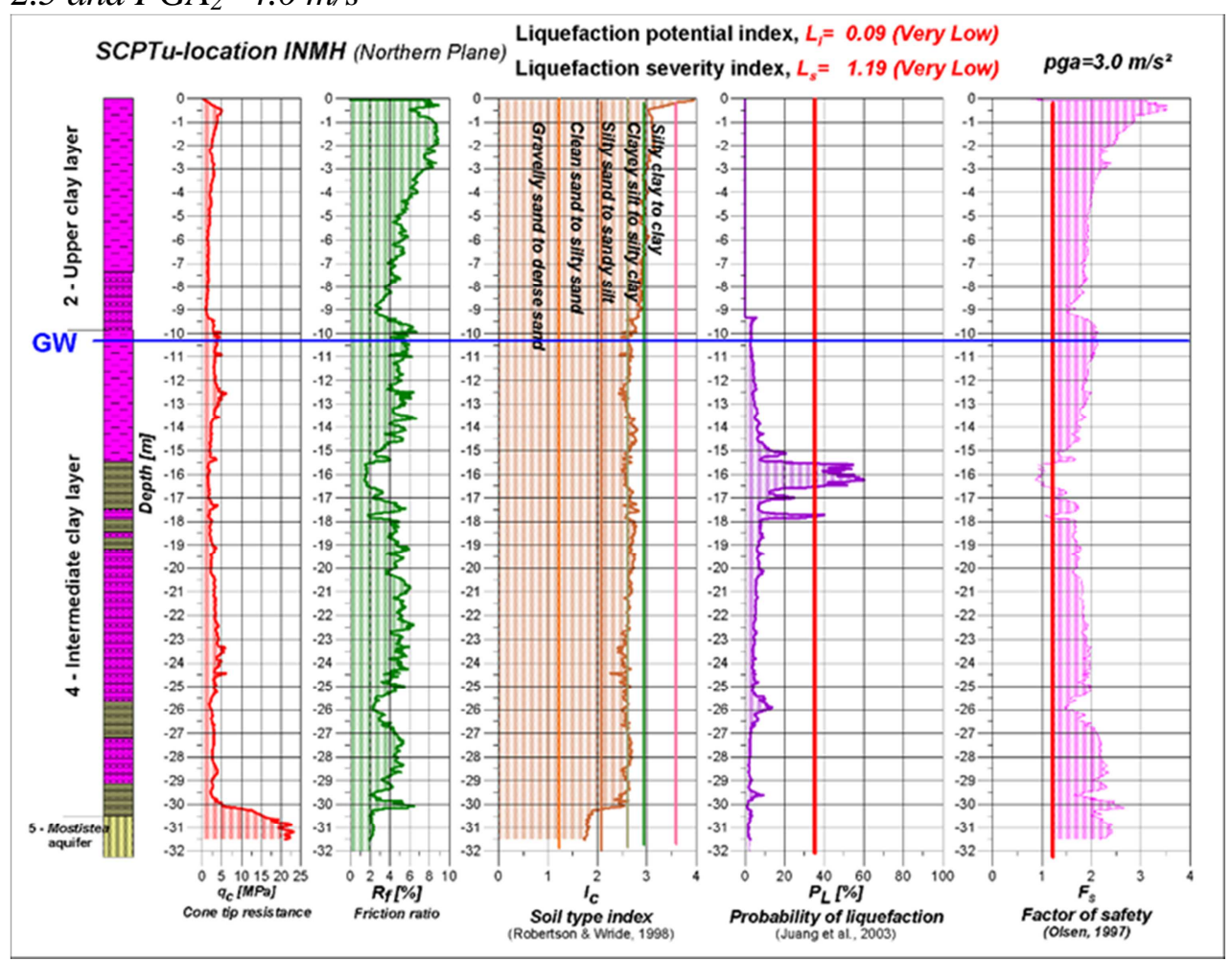

a) 


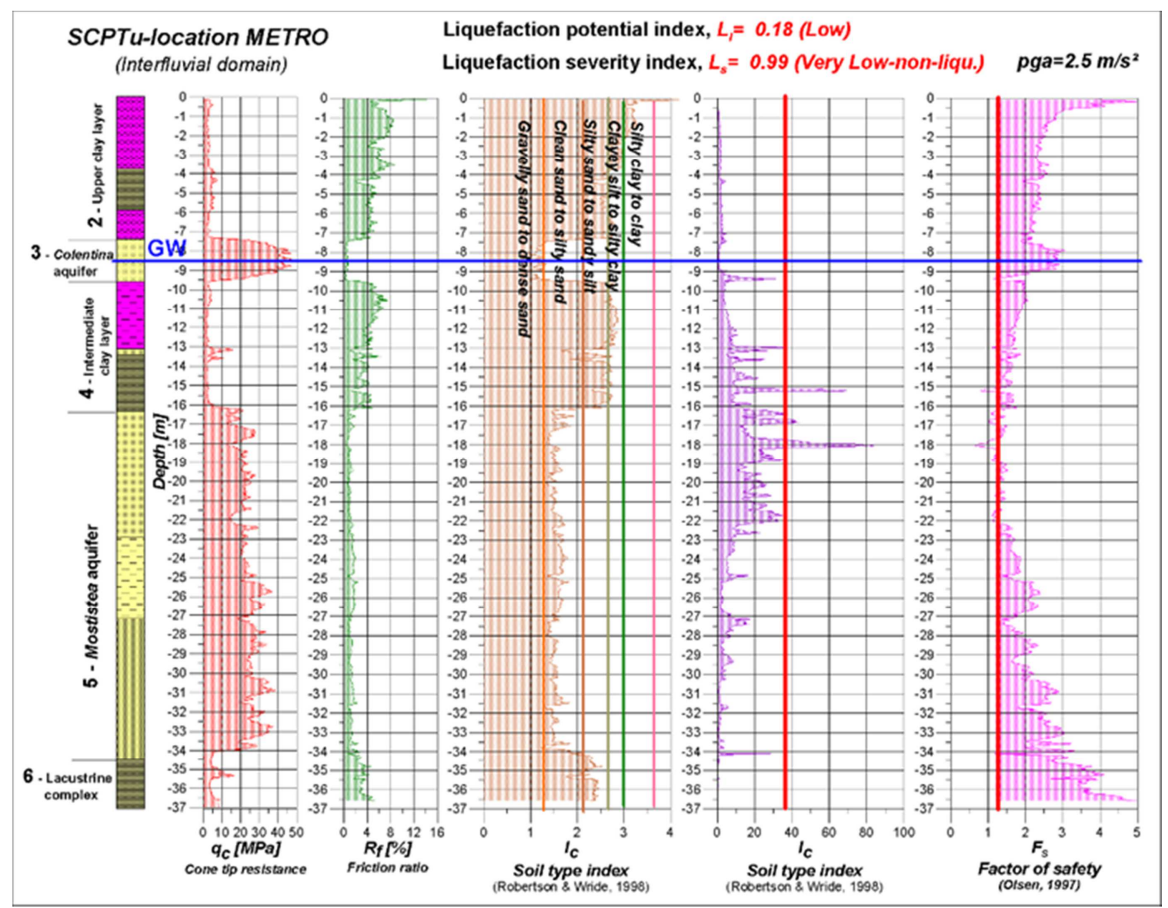

b)

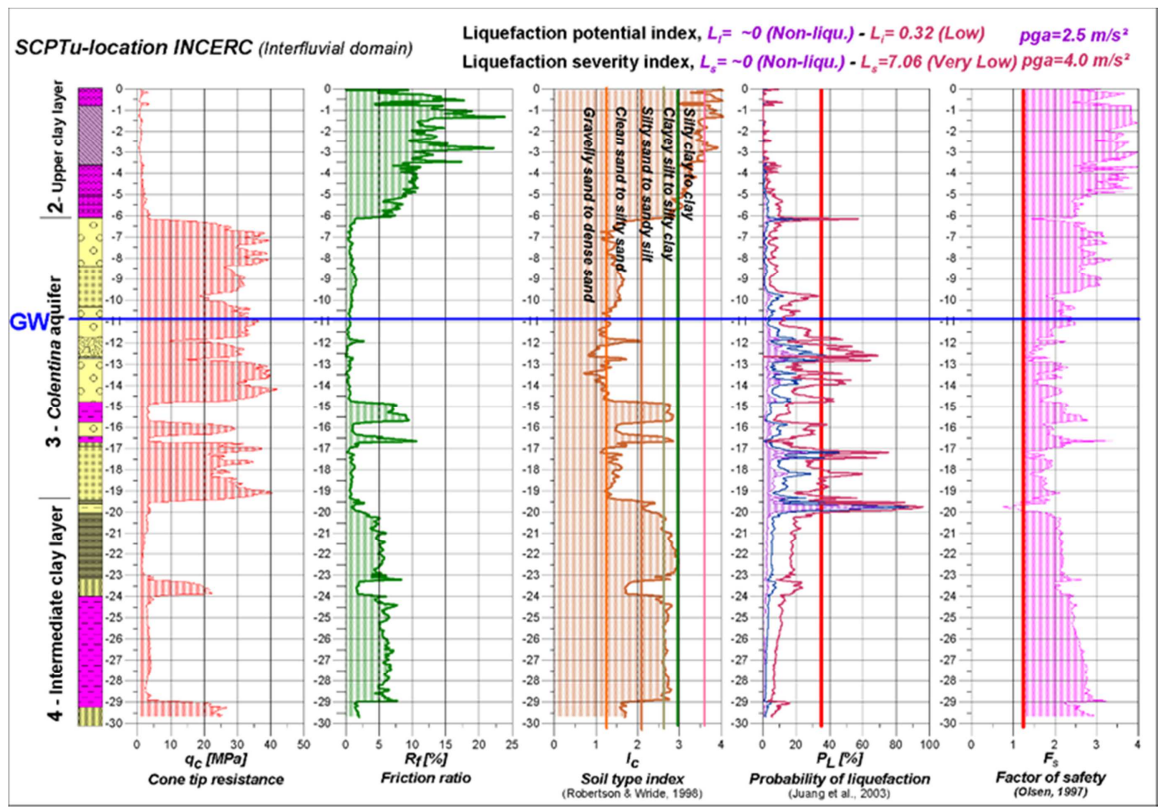

c)

It is worth to note that all 3 locations presented in Figure 6 are located to the north-west of Bucharest, outside the meadow area of Colentina River.

As for the liquefaction evaluation in Figure 6 we can observe that for these wells we have water table at the deepest level, between 8.5 and $10.5 \mathrm{~m}$. For the last site at INCERC (Figure 6c): one for a site acceleration of $2.5 \mathrm{~m} / \mathrm{s}^{2}-$ and liquefaction potential index as well as probability of liquefaction are close to 0 . For $\mathrm{PGA}_{2}=4.0 \mathrm{~m} / \mathrm{s}^{2}$ - both parameters are still very low. 


\section{Discussion of the Liquefaction Potential for Bucharest City}

Based on the SCPTu-data and the liquefaction potential index $\mathrm{Li}$, as well as on the liquefaction severity index Ls, maps for Bucharest were prepared, showing the areas with higher risk to liquefaction process during strong earthquakes like the 1977 one.

The map for the liquefaction potential index $\mathrm{Li}$ for Bucharest is presented in Figure 7, by interpolation of the Li-values obtained at the ten SCPTu-locations and additional 4 phantom locations with adopted values for Li. The analysis was performed taking into account the magnitude of this 1977 Vrancea earthquake (Mw=7.4) and a PGA distribution deduced by Sokolov and Bonjer (2006) for Bucharest central area.

It can be observed that a larger area with low potential $(\mathrm{Li}>2)$ extends SENW, comprising the Dambovita river meadow and the eastern part of the Colentina river meadow. Within this larger area, two local areas - one in the Tineretului Park and the other in the Eroilor Park - around the locations TINE and EROI, areas with "high" potential $(\mathrm{Li}>8)$ were contoured. Around the BAZI and the AGRO locations, an area with a moderate potential index $(\mathrm{Li}>5)$ was outlined.

Figure 7. Contour Map of the Liquefaction Potential Index Li for Bucharest City, Computed for Evaluated PGA-Values Corresponding to 1977 Earthquake (Table 1) and a Return Period of 475 Years

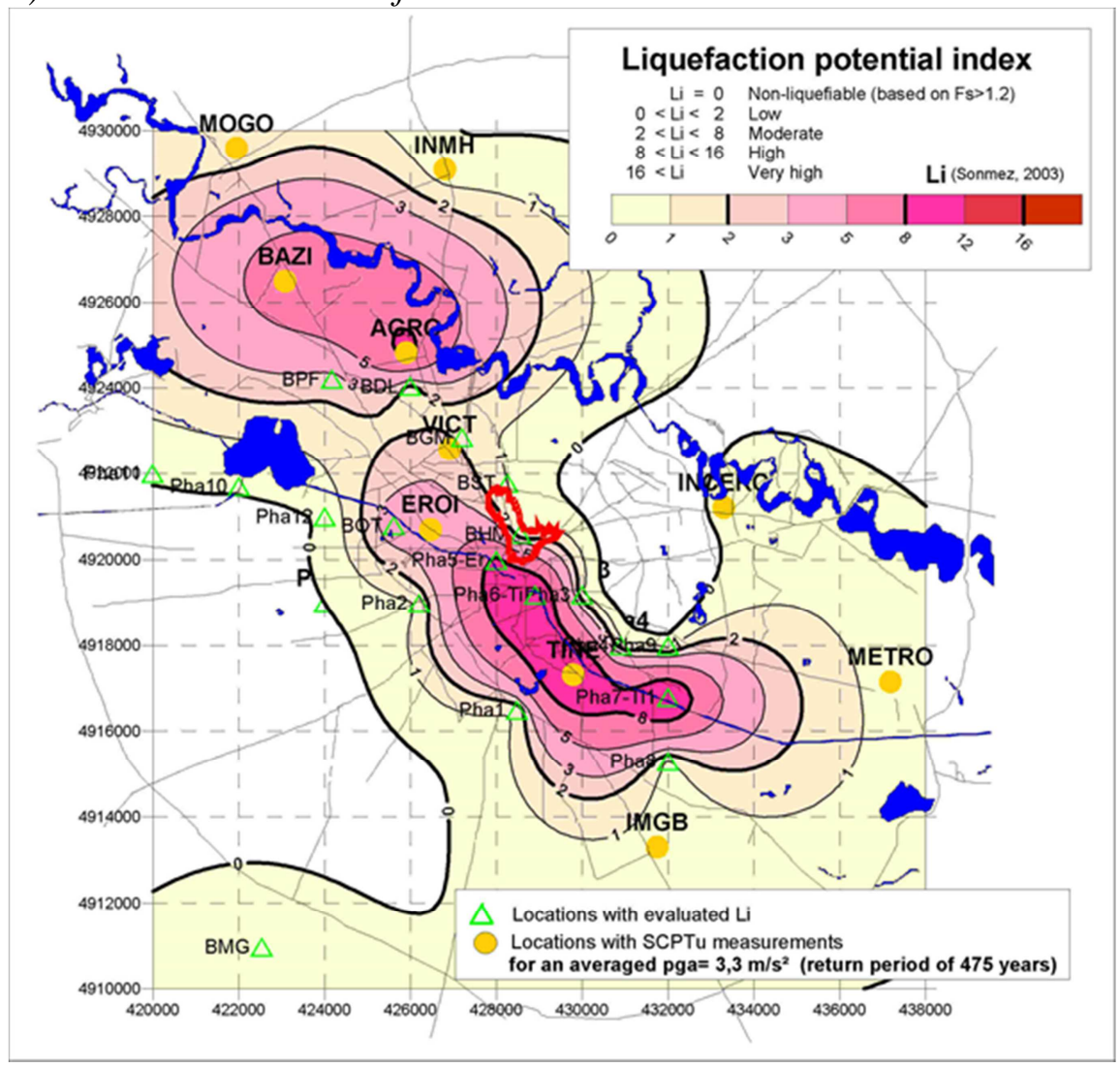


We have produced here a liquefaction potential map for an average of $\mathrm{PGA}=3.3 \mathrm{~m} / \mathrm{s}^{2}$, with a return period of 475 years. However other probabilistic maps, displaying the liquefaction potential for the shaking expected in a 100-year time window accounting for all earthquakes and the likelihoods of each occurring can be performed as well.

\section{Conclusions}

The liquefaction probability was calculated for each of the 10 SCPTu locations on the basis of the CPT data (tip resistance and sleeve friction) using empirical methods. Simplified procedures, originally proposed by Seed and Idriss (1971) is still one of the most frequently used, being based on stress calculations, namely as the ratio between the cyclic stress ratio (CSR) and the cyclic resistance ratio (CRR). The method has been revised and updated and a number of similar methods have been adapted for the calculation of CRR during the years. The Olsen (1997) method is used in the present study because it was believed to be most appropriate for the raw data and conditions available in Bucharest.

Calculations were carried out on each SCPTu location but with different input data, depending on the site.

1. On each locations the basic data used as input consisted in the actual shearwave velocity computed in the same location as well as the ground motion acceleration computed in place for an Vrancea earthquake with magnitude $\mathrm{Mw} \geq$ 7.4 ( as for the great earthquake from 04.03.1977).

2. Some calculations are made with different groundwater levels, which document the influence of the groundwater fluctuations on the occurrence of liquefaction, like for location Bazi (Figure 4c). It can be seen that at a higher $\mathrm{GW}$ level, the liquefaction probability is significantly higher than for the lower level of groundwater. Also for the lower range, the liquefaction is significant, clearly above the limit value of $35 \%$.

3. The influence of elevated PGA levels, i.e. events of larger magnitudes, are documented for an increased likelihood of liquefaction. At the site INCERC (Figure $6 \mathrm{c}$ ) there are used two levels of maximum acceleration: $\mathrm{PGA}_{1}=2.5 \mathrm{~m} / \mathrm{s}^{2}$ and $\mathrm{PGA}_{2}=4.0 \mathrm{~m} / \mathrm{s}^{2}$. For the latter value a greater risk of liquefaction can be seen in the graphics.

4. The importance of the exact knowledge of the groundwater levels in a region, especially in urban areas, in connection with a correct classification of the liquefaction potential and the seismic hazards mapping is pointed out. At the same time, historical high and low levels of the groundwater must be known in order to correctly assess the liquefaction risk.

In the present paper it was stressed that groundwater level changes influence the ground response strongly and cannot be neglected for site effect analyses, the same effect was noted by previous works (Ehret et al. 2010), which were using other methods.

In the presence of confined aquifers, liquefaction can take place in the subsurface. This results in attenuation of shear wave propagation and can reduce 
duration and amplitude of ground shaking and ground water level changes, even sezonal variations, should be considered for seismic microzonation studies.

The main goals of this research direction could be achieved if additional measurements during moderate to strong Vrancea earthquakes can be adopted for an overall assessment. The developed groundwater flow model is functional and enables the answer to a main problem of being able to forecast groundwater levels for future times and at certain locations in Bucharest. However additional, denser data on anthropogenic influences in the city center area and additional continuous groundwater level measurement data in the urban area are required. The question of the influence of different groundwater levels and thus different degrees of water saturation within the sand layers on the shear wave velocity could be only partially answered by the SCPTu measurements, but further laboratory investigations by means of resonant column tests will provide additional data.

The map of liquefaction potential index was computed for all Bucharest area and we can see 3 locations with great liquefaction index at TINE and EROI, as well as at BAZI locations. The locations at EROI are very sensitive to liquefaction, due to the present geotechnical parameters and actually an incident has happened during the construction stage at the underground station Eroilor in 2015, exactly in the same area. The whole incident is described in Annex 1.

After our observations from Annex 1 a new study demonstrates the effects of the same incident. The study of Gheorghe et al. (2019) reached to the same conclusions as ours (presented in Annex 1): the construction of the metro station in the Eroilor area (TINE location) posed a threat to the structures aboveground, due to the geotechnical conditions and annual ground movement recorded prior to the incident of the metro in December 2015. Future similar events might still occur in the case of underground constructions in Bucharest.

Two of the locations, where a high potential index was computed in Table 3, are also mentioned in a recent paper that is presenting the vertical displacements map of Bucharest, obtained using Sentinel-1 data, trends at city scale. The 2 locations TINE and EROI in the present study have been put into evidence by Radutu et al. (2020) as 2 zones, situated just near the Dâmbovița river, with measurable subsidence areas, which make them unfit for constructions.

The question of the influence of magnitude, frequency content and duration of the Vrancea earthquakes on changes in pore water pressure in the Colentina sand and gravel layer remain a task for the future, that must be pursued as it was demonstrated a clear link between our measurements and seismic hazard in a high populated area as Bucharest City.

\section{References}

Bala A, Raileanu V, Zihan I, Ciugudean V, Grecu B (2006) Physical and dynamic properties of the shallow sedimentary rocks in the Bucharest Metropolitan Area. Romanian Reports in Physics 58(2): 221-250.

Bala A, Hannich D, Ritter JRR, Ciugudean-Toma V (2011) Geological and Geophysical Model of the Quaternary Layers based on in situ measurements in Bucharest, Romania. Romanian Reports in Physics 63(1): 250-274. 
Bretotean M, Reich C, Baldovin M (1986) Problems of groundwater abstraction optimization from shallow and medium deep aquifers in the city area of Bucharest (in Romanian). Studii si Cercetari - Hidrologie (Bucuresti) 53: 127-142.

Bretotean M (2001) Phreatic level variations in Bucharest between 1973-2001 (in Romanian). Internal Report. Bucharest: National Institute for Meteorology and Hydrology.

Chen CJ, Juang CH (2000) Calibration of SPT- and CPT-based liquefaction evaluation methods. In PW Mayne, R Hryciw (eds.), Innovations and Applications in Geotechnical Site Characterization, 49-64. Geotechnical Special Publication 97.

Ciugudean V, Martinof D (2000) Geological, geomorphological and hydrogeological conditions in the city area of Bucharest. Internal Report. Bucharest: S.C. Metroul S.A.

Ciugudean-Toma V, Stefanescu I (2000) Engineering geology of the Bucharest city area, Romania. In Proceedings of IAEG -2006 Engineering Geology for Tomorrow's Cities. Paper no. 235.

Ehret D, Hannich D, Schmitt S, Huber G (2007) Numerical modelling of side effects Influences of groundwater level changes. In Proceedings of the $1^{\text {st }}$ IASME/WSEAS International Conference on Geology and Seismology (GES'07). Portoroz, Slovenia, May 15-17.

Ehret D, Rohn R, Hannich D, Grandas C, Huber G (2010) Numerical modelling of seismic site effects incorporating non-linearity and groundwater level changes. Journal of Earth Science 21(6): 931-940.

Gheorghe M, Armaș I, Dumitru P, Călin A, Bădescu O, Necşoiu M, (2019) Monitoring subway construction using Sentinel-1 data: a case study in Bucharest, Romania. International Journal of Remote Sensing 41(7): 2644-2663.

Hannich D, Hötzl H (2008) Teilprojekt B7: Hyrogeologie und Standorteffekte bei Erdbeben in Bukarest Arbeitsbericht Phase IV (2005-2007), Sonderforschungsbereich 461. (Subproject B7: hyrogeology and standard effects on earthquakes in Bucharest Work report phase IV (2005-2007), collaborative research center 461). Starkbeben: Von geowissenshaftlichen Grundlagen zu IngenieurmaBnahmen, Geologisches Institut, Abt. Hydrogeologie, Universitätsverlag Karlsruhe.

Hannich D, Orlowsky D (2014) Shear-wave velocities of the quaternary layers, determined by multi-offset vertical seismic profiling (MOVSP) in Bucharest, Romania. Romanian Reports in Physics 66(4): 1207-1225.

Hannich D, Hötzl H, Ehret D, Bretotean M, Danchiv A, Ciugudean V (2005) The impact of hydrogeology on earthquake ground motion in soft soils. In Proceedings of the International Conference $250^{\text {th }}$ Anniversary of the 1755 Lisbon Earthquake, 358361.

Hannich D, Hötzl H, Cudmani R (2006a) The influence of groundwater on damage caused by earthquakes - An overview (in German). Grundwasser 11(4): 286-294.

Hannich D, Huber G, Ehret D, Hötzl H, Balan S, Bala A, et al. (2006b) SCPTu-Techniques used for shallow geologic/hydrogeologic site characterization in Bucharest, Romania. In ESG 2006 - Third International Symposium on the Effects of Surface Geology on Seismic Motion 1, 981-992.

Hannich D, Hötzl H, Ehret D, Huber G, Danchiv A, Bretotean M (2007) Liquefaction probability in Bucharest and influencing factors. In Proceedings of the International Symposium on Strong Vrancea Earthquakes and Risk Mitigation, 205-221. Bucharest, Romania.

Ishihara K, Perlea V (1984) Liquefaction-associated ground damage during the Vrancea earthquake of March 4, 1977. Soils and Foundations, 24(1): 90-112. 
Iwasaki T, Arakawa T, Tokida K (1982) Simplified procedures for assessing soil liquefaction during earthquakes. In Proceedings of the Conference on Soil Dynamics and Earthquake Engineering, 925-939. Southampton, UK.

Juang CH, Yuan H, Lee DH, Lin PS (2003) Simplified CPT-based method for evaluating liquefaction potential of soils. Journal of Geotechnical and Geoenvironmental Engineering 129(1): 66-80.

Kramer SL (1996) Geotechnical earthquake engineering. Upper Saddle River, NJ: Prentice Hall.

Lee D-H, Ku C-S, Yuan H (2003) A study of the liquefaction risk potential at Yuanlin, Taiwan. Engineering Geology 71(1-2): 97-117.

Li DK, Juang CH, Andrus RD (2006) Liquefaction potential index: a critical assessment using probability concept. Journal of GeoEngineering 1(1): 11-24.

Liteanu E (1952) Geology of Bucharest city area. In Com. Geol. St. Tehn. Econ, series E, no. I. Bucharest (in Romanian).

Lungu D, Aldea A, Moldoveanu T, Ciugudean V, Stefanica M (1999) Near-surface geology and dynamic properties of soil layers in Bucharest. In F Wenzel, D Lungu, O Novak (eds.), Vrancea Earthquakes: Tectonics, Hazard and Risk Mitigation, 137148. Dordrecht: Kluwer Academic Publishers.

Mandrescu N, Radulian M, Marmureanu Gh (2004) Site conditions and predominant period on seismic motion in the Bucharest urban area. Revue Roumaine de Geophysique 48: 37-48.

Mutihac V (1990) Geologic structure of Romania (in Romanian). Bucharest: Edit. Tehnică.

Olsen RS (1997) Cyclic liquefaction based on the cone penetration test. In TL Youd, IM Idriss (eds.), Proceedings of the NCEER Workshop of Evaluation of Liquefaction Resistance of Soils, 225-276. Buffalo, NY: State University of New York at Buffalo.

Radutu A, Venvik G, Ghibus T, Gogu CR (2020) Sentinel-1 data for underground processes recognition in Bucharest City, Romania. Remote Sensing 12(24): 4054.

Robertson P, Wride C (1998) Evaluating cyclic liquefaction potential using the cone penetration test. Canadian Geotechnical Journal 35(Jan): 442-459.

Seed HB, Idriss IM. (1971) Simplified procedure for evaluating soil liquefaction potential. Journal of the Soil Mechanics and Foundations Division 97(9): 1249-1273.

Sokolov V, Bonjer K-P (2006) Modeling of distribution of ground motion parameters during strong Vrancea (Romania) earthquakes. In Proceedings of First European Conference on Earthquake Engineering and Seismology, paper no. 363. Geneva, Switzerland, 3-8 September 2006.

Sokolov V, Bonjer K-P, Wenzel F, Grecu B, Radulian M (2008) Ground-motion prediction equations for the intermediate depth Vrancea (Romania) earthquakes. Bulletin of Earthquake Engineering 6(3): 367-388.

Sonmez H (2003) Modification to the liquefaction potential index and liquefaction susceptibility mapping for a liquefaction-prone area (Inegol-Turkey). Environmental Geology 44(7): 862-871.

Sonmez H, Gokceoglu C (2005) A liquefaction severity index suggested for engineering practice. Environmental Geology 48(1): 81-91.

Von Steht M, Jaskolla M, Ritter JRR (2008) Near surface shear wave velocity in Bucharest, Romania. Natural Hazards and Earth System Sciences 8(6): 1299-1307.

Yuan H, Yang SH, Andrus RD, Juang CH (2004) Liquefaction-induced ground failure: a study of the Chi-Chi earthquake cases. Engineering Geology 71(1-2): 141-155. 


\section{Annex 1}

In the end of the present paper we should brought into discussion a serious incident that occurred in 2015 on the Line 5 (in construction at that time) of the underground in Bucharest, incident that unfortunately proved that the conditions of the shallow layers and the groundwater level are distributed as we presented and the occurrence of a liquefaction along the Dambovița river is a serious threat for the all inhabitants in the area.

The two Tunnel Boring Machine (TBM)s, the giant equipment that digs the subway tunnels on the underground line 5 to Drumul Taberei zone, arrived at the entrance to "Eroilor 2" station, and on Friday 11.11.2015 at noon the first TBM named "Sf. Varvara", broke the molded wall of the future station. A little later about 500 cubic meters of water, gravel and sand poured into the station (which is at $22 \mathrm{~m}$ depth), leaving behind a "gap" under the concrete slab under the Bv. Eroilor Sanitari. When the TBM came out at the end of the tunnel, it broke that molded wall and a lot of water and alluviums entered the station, according to sources from the construction site.

This mass has practically moved from the areas where the collapse is seen on the surface and left a gap in which the plaque of the road collapse with $30-40 \mathrm{~cm}$ from surface.

Figure 8. Schematic Set of the Area of the Incident

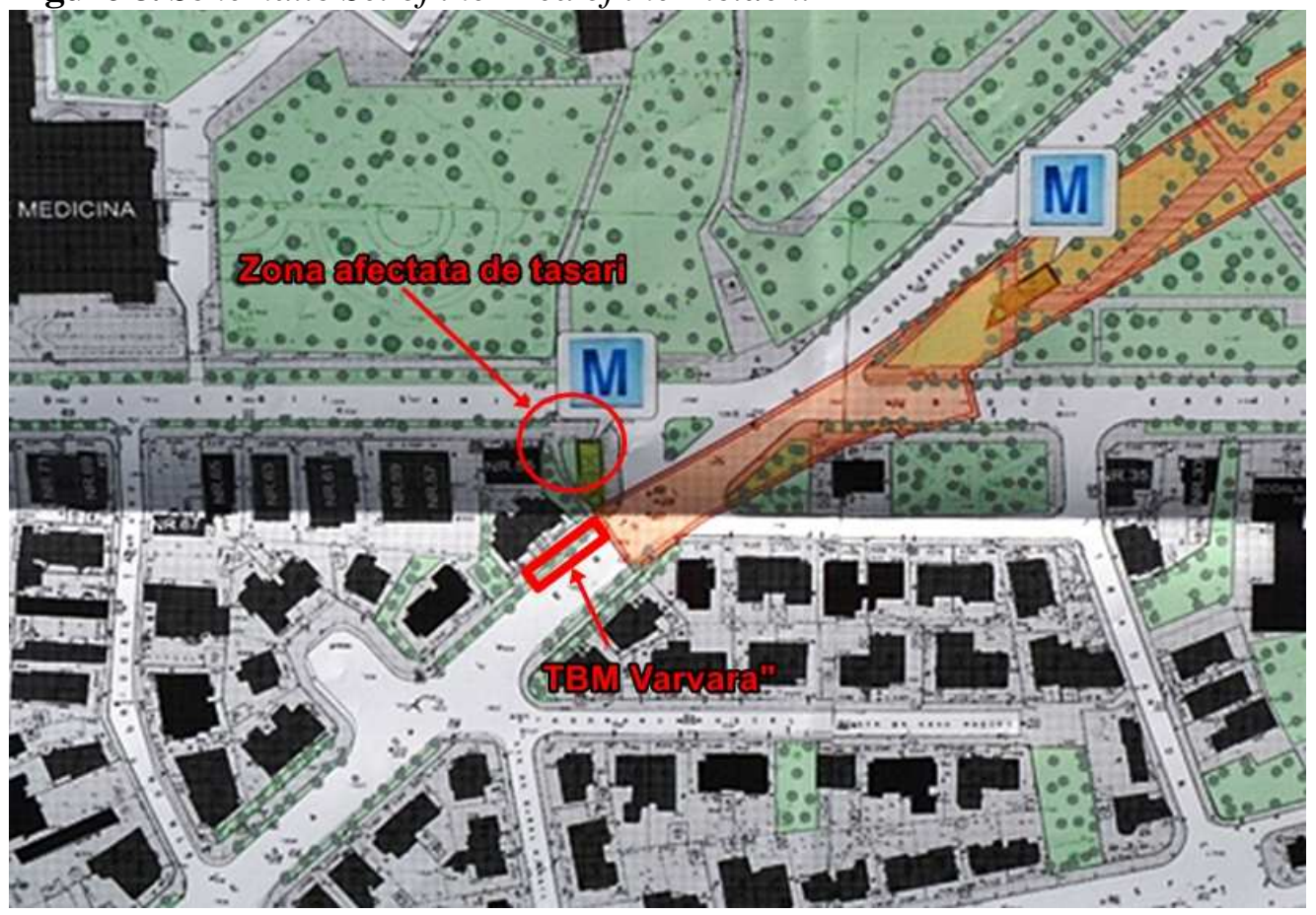

Source: https://monitorizari.hotnews.ro/stiri-infrastructura_articole-20665433-intamplat-metrousurpat-pamantul-eroilor-acolo-unde-sapa-cartitele-magistrala-5.htm.

According to other sources close to the situation, the large amount of water that collected and caused other alluvium also came from a depletion well (water drainage well) that was damaged when the TBM machine entered the station, and 
the water entered the groundwater and the soil in the area softened. After the incident, when the first settlements appeared under the road, the builder filled the gap with almost 70 cubic meters of concrete, but the compaction phenomenon continued and another 120 cubic meters of concrete were poured. Eventually, the settlement stagnated. For safety reasons, however, the authorities opted to evacuate some 14 persons from the two nearby buildings.

Figure 9. Photo after the Incident with Collapse of the Road and the 2 Affected Buildings across the Road

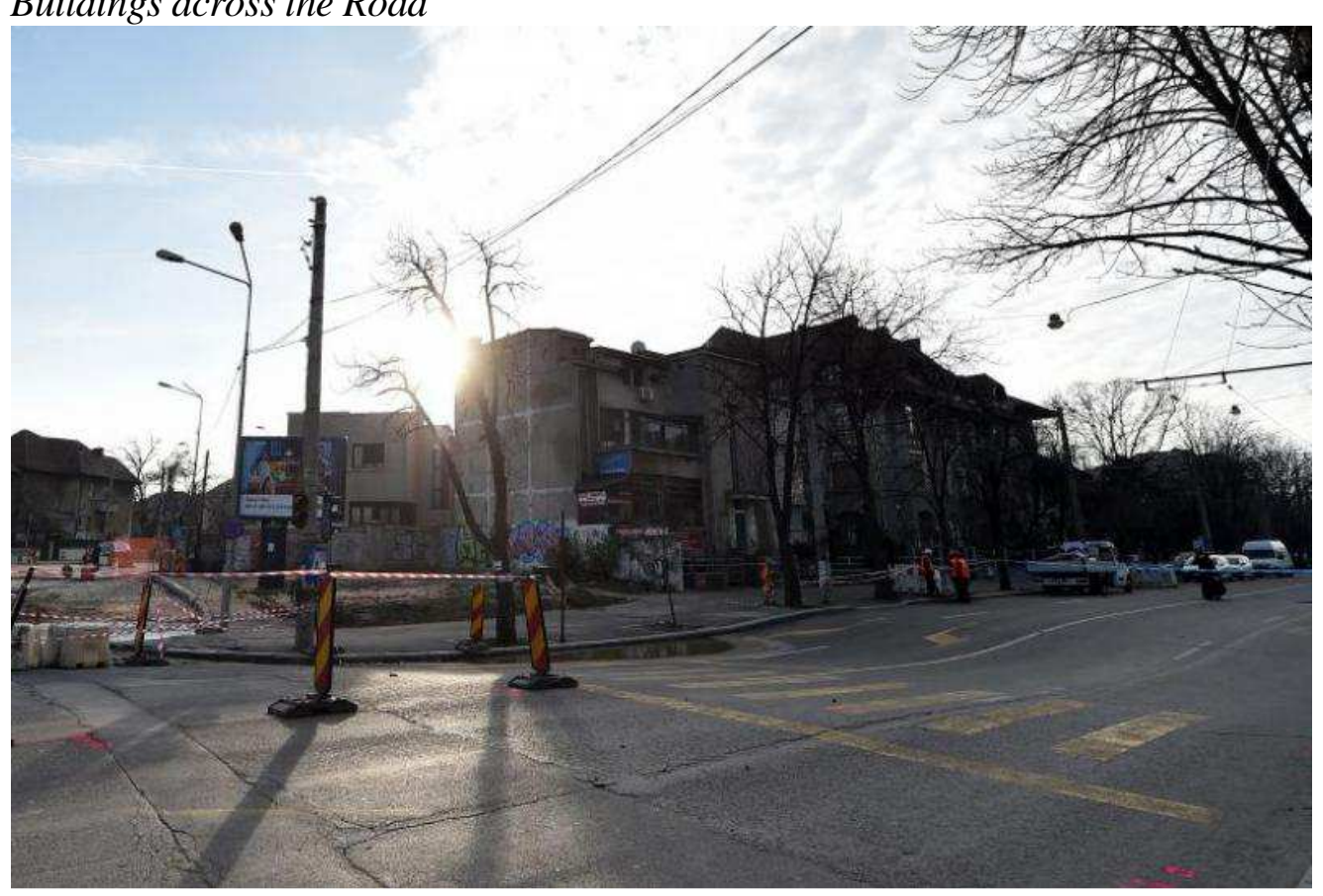

Source: Agerpres.

That was almost all we have found about the incident from the media of that time.

In our rough interpretation the 500 cubic meters of water and alluvium could not be replaced completely by only 200 cubic meters of concrete that was put under the road in an effort of stabilizing the ground. The situation has much in common with the liquefaction phenomenon presented above and it involves a great quantity of water mixed with silt and gravel which acted as a thick liquid and pour into the underground station by the hole in the molded wall that was dug by the TBM.

No earthquake was involved in the incident, but the TBM in its movement created a lot of ground-shaking of the underground, enough to mobilize the mass of water and alluviums and to make it move to the underground station at Eroilor 2.

The situation was serious enough so that the constructor took some immediate measures in order to stabilize the ground, close the traffic and emptied 2 buildings which were in a danger of collapsing. Although the promises of the constructors 
were to rebuild the area in a couple of months, it took more than a year before the traffic was opened at surface and the construction of line 5 was resumed.

But the situation of the two constructions just across the street was not good, as they were still uninhabitable.

Eventually both of them were refitted after more than one and a half year after the incident.

This incident was presented as it involves the same material and conditions as a real liquefaction and acted in the same way and it took place in the underground station named Eroilor (Figure 9), which is the exact spot in which our paper predicted a high probability of a liquefaction to occur (see Figure $4 \mathrm{~b}$ and Figure 8 - zone EROI).

After we have proposed this incident on the M-5 subway line, as a proof of existence of geotechnical conditions able to determine an induced liquefaction of the terrain, we have new scientific proofs recorded and interpreted by (Gheorghe et al. 2019). They have used a medium-resolution SAR imagery for monitoring subsidence due to tunneling which was used before to detect fine movements of the terrain along subway lines.

In the case of the M-5 subway belt, processing two data stacks each containing more than 160 Sentinel-1 images, revealed movement patterns associated with underground construction works, consisting of cumulative subsidence values of up to $20 \mathrm{~mm}$ with an average yearly velocity of up to 8 $\mathrm{mm} /$ year (Gheorghe et al. 2019) prior and near the moment of the technical incident at Eroilor stations described in Annex 1.

The subsidence values of $-40 \mathrm{~mm}$ on top of the metro station reported by the authorities immediately after the event could not be detected due to technical problems, but after that there are recorded proofs that the terrain in the area begin to raise very slow and it was not gaining the initial values. 
